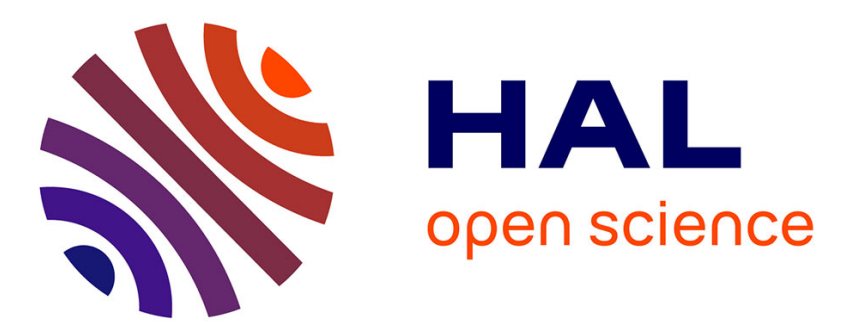

\title{
Costs of Mediterranean and Western dietary patterns in a Spanish cohort and their relationship with prospective weight change.
}

Celeste N Lopez, Miguel A Martinez-Gonzalez, Almudena Sanchez-Villegas, Alvaro Alonso, Adriano M Pimenta, Maira Bes-Rastrollo

\section{To cite this version:}

Celeste N Lopez, Miguel A Martinez-Gonzalez, Almudena Sanchez-Villegas, Alvaro Alonso, Adriano M Pimenta, et al.. Costs of Mediterranean and Western dietary patterns in a Spanish cohort and their relationship with prospective weight change.. Journal of Epidemiology and Community Health, 2009, 63 (11), pp.920-n/a. 10.1136/jech.2008.081208 . hal-00477875

\section{HAL Id: hal-00477875 https://hal.science/hal-00477875}

Submitted on 30 Apr 2010

HAL is a multi-disciplinary open access archive for the deposit and dissemination of scientific research documents, whether they are published or not. The documents may come from teaching and research institutions in France or abroad, or from public or private research centers.
L'archive ouverte pluridisciplinaire HAL, est destinée au dépôt et à la diffusion de documents scientifiques de niveau recherche, publiés ou non, émanant des établissements d'enseignement et de recherche français ou étrangers, des laboratoires publics ou privés. 


\section{(TITLE PAGE)}

\section{Costs of Mediterranean and Western dietary patterns in a}

\section{Spanish cohort and their relationship with prospective}

\section{weight change.}

Running title: Costs of Mediterranean and Western dietary patterns and weight change

Celeste N López, Miguel A Martínez-González, Almudena Sanchez-Villegas, Alvaro Alonso, Adriano M Pimenta, Maira Bes-Rastrollo

- $\quad$ Harvard Medical School, Boston, United States (CNL)

- $\quad$ Dept. Preventive Medicine and Public Health. School of Medicine. University of

Navarra, Pamplona, Navarra, Spain (CNL, MAMG, ASV, AA, AMP, MBR)

- Dept. of Clinical Sciences, Universidad de Las Palmas de Gran Canaria, Gran Canaria, Spain (ASV)

- Dept. of Epidemiology and Community Health, University of Minnesota,

Minneapolis, United States (AA)

- Dept. of Maternal and Child Nursing and Public Health, Universidade Federal de Minas Gerais, Minas Gerais, Brazil (AMP)

\section{Correspondence and Reprints:}

Dr. Maira Bes-Rastrollo

Dept. Preventive Medicine \& Public Health Univ. Navarra. 
Irunlarrea 1. 31008 Pamplona. Spain

Tel: 0034-948425600 (6602),

Fax: 0034-948425649

E-mail: $\underline{\text { mbes@ } @ \text { unav.es }}$

Key Words: price; affordability; food frequency; weight gain; obesity; prospective, dietary patterns, PCA

Word Count: 3873

References: 50 
(ABSTRACT)

Short abstract (243 words; without characteristics of the dietary patterns)

Background: There is a scarcity of studies evaluating the relationship between food costs and adherence to different food patterns and obesity.

Methods: This was a dynamic cohort of Spanish university graduates ( $\mathrm{n}=17197$ for the crosssectional baseline assessment and 11195 for the prospective follow-up analyses). Mean age was 38.6 (SD: 12.2) and 60\% of participants were women. A 136-item food frequency questionnaire previously validated in Spain was used. Principal component analysis (PCA) was used to derive dietary patterns. Average cost of food was calculated from official Spanish government data. Self-reported weight was previously validated in the cohort. Body weight was assessed both at baseline and during follow-up.

Results: PCA identified two dietary patterns, designated as Western and Mediterranean. Participants with highest scores on the Western dietary pattern (fifth quintile vs. first quintile), spent less money:-0.64 € (-0.80 \$) per $1000 \mathrm{kcal}(95 \% \mathrm{CI}:-0.68 €$ to $-0.61 €, p$ for trend $<0.001$ ) on their daily food costs whereas the opposite was true for the Mediterranean dietary pattern: $+0.71 €(+0.90 \$)(95 \% \mathrm{CI}:+0.67 €$ to $+0.74 €, \mathrm{p}$ for trend $<0.001)$. After adjusting for dietary pattern scores and other potential confounders higher daily food costs consumption were significantly associated with greater weight gain.

Conclusions: These data suggest that a Mediterranean dietary pattern is more expensive to follow than a Western dietary pattern. This economic barrier should be considered when counseling patients about following a healthy diet since cost may be a prohibitive factor. 


\section{Long Abstract (including all the reviewer's suggestions;}

\section{8 words)}

\section{Background:}

There is a scarcity of studies evaluating the relationship between food costs and adherence to different food patterns. Prospective assessments of dietary costs and body weight change are also needed. Thus, we examined whether costs of daily food consumption were associated with dietary patterns derived from principal component analysis (PCA) and whether costs were prospectively associated with weight gain.

Methods: This was a dynamic cohort of Spanish university graduates ( $\mathrm{n}=17197$ for the crosssectional baseline assessment and 11195 for the prospective follow-up analyses). Mean age was 38.6 (SD: 12.2) and 60\% of participants were women. A 136-item food frequency questionnaire previously validated in Spain was used. Average cost of food was calculated from official Spanish government data. Self-reported weight was previously validated in the cohort. Body weight was assessed both at baseline and during follow-up.

Results: PCA identified two dietary patterns, designated as Western and Mediterranean. Western dietary pattern scores represented high intakes of red and processed meat, eggs, sauces, pre-cooked foods, fast-food, caloric soft drinks, commercial sweets, whole-fat dairy products and potatoes, whereas the Mediterranean pattern reflected high intakes of olive oil, poultry, fish, low-fat dairy, legumes, fruit and vegetables. Participants with highest scores on the Western dietary pattern (fifth quintile $v s$. first quintile), spent less money:-0.64 $€(-0.80 \$)$ per $1000 \mathrm{kcal}(95 \% \mathrm{CI}:-0.68 €$ to $-0.61 €, p$ for trend $<0.001)$ on their daily food costs whereas the opposite was true for the Mediterranean dietary pattern: $+0.71 €(+0.90 \$)(95 \%$ $\mathrm{CI}:+0.67 €$ to $+0.74 €, \mathrm{p}$ for trend $<0.001)$. After adjusting for dietary pattern scores and other potential confounders higher daily food costs consumption were significantly associated with greater weight gain. 
Conclusions: These data suggest that a Mediterranean dietary pattern is more expensive to follow than a Western dietary pattern. This economic barrier should be considered when counseling patients about following a healthy diet. Upstream measures are probably needed because cost may be a prohibitive factor for underprivileged sectors of the population. 


\section{(TEXT)}

\section{INTRODUCTION}

The cost of food is one factor that influences people's choices in diet, in addition to culture, taste and convenience [1]. The choices individuals make contribute to adherence to dietary patterns. [2] There has been increasing evidence that patterns that adhere closely to the Mediterranean diet, rich in monounsaturated fatty acids found in olive oil and omega-3 fatty acids found in fish have protective health effects. [3-8] Other patterns, such as the modern "Western" diet, high in trans fats and refined sugars, have detrimental effects including the relationship with the current obesity epidemic. [9-12]

There have been a number of investigations examining the relationship of cost of food and energy-density, and it has been seen that low-energy-density diets are associated with higher cost of daily food consumption [13-15] and also with higher nutritional quality [16-19] and lower BMI. [20] Implementing a Mediterranean diet, however, has not been associated with increased total costs if subjects replace expensive high-energy-density foods such as red meat and desserts, with equally costly low-energy-density foods such as vegetables and fish. [21] The World Health Organization recommends avoiding high energy density foods due to their low nutritional quality and high caloric content. [22] However, the costs of low-energydensity foods appear to be increasing relatively to the price of high-energy-density foods. [23] One of the possible reasons to explain these results is based on the idea that high-energy dense fast-foods are of low cost.

The concept of energy-density (grams per weight) is useful for providing a framework of understanding energy costs, however practical application of this concept must take into account dietary patterns in order to be applicable to an individual's understanding, and as a consequence to facilitate the change of his/her food choices. Examining dietary patterns in a 
manner that is readily understandable to the public and clinicians is an acceptable method for providing applicable data. Therefore, we decided to examine the costs of observed dietary patterns in a Mediterranean cohort. A population of Mediterranean subjects is especially interesting in light of the increasing trend towards a more modern Western diet in this population over the recent years. [24, 25] To our knowledge, an association between costs of dietary patterns defined by principal component analysis, in a Mediterranean area, has not been previously performed. Further, while previous studies relating costs to dietary patterns have used cross sectional designs, the unique capacity of the dynamic cohort of our Mediterranean population allows for a novel longitudinal design to also assess cost of daily food consumption and subsequent body weight change.

\section{METHODS}

\section{Participants}

The methods for the recruitment and solicitation of data from the participants of the prospective cohort study "Seguimiento Universidad de Navarra" (Follow-up Study of the University of Navarra) (SUN) have been described in detail in previous publications. [26, 27] The SUN study was designed to determine associations between diet and the occurrence of chronic conditions such as obesity through a self-administered questionnaire mailed every two years. The SUN participants are all university graduates. The recruitment of this dynamic cohort began in December 1999 and as of the time this analysis was performed in February 2008 it included 19057 subjects with a mean age of 38.6 (SD: 12.2) and 60\% women. After excluding for extremes of caloric intake ( $<800$ or $>4000 \mathrm{kcal} /$ day for men, $<500$ or $>3500$ $\mathrm{kcal} /$ day for women $)(\mathrm{n}=1700)$ and biologically implausible values for height and weight $(n=160), 17197$ subjects remained. These subjects were analyzed for the association between 
costs and dietary pattern. Analysis for the association between costs and weight change was done among those subjects who answered the baseline questionnaire before May 2005 and returned the follow up questionnaires $(n=12196)$. Follow-up questionnaires were returned at two, four and/or six years after baseline, dependent on the time of initial enrollment (overall retention rate was approximately $88 \%)$. After excluding pregnant women $(n=1001)$ who were pregnant either at baseline or during follow-up taking into account that pregnant women increase their body weight during pregnancy. Unfortunately, we do not have the information about breast feeding. However, since we excluded pregnant women either at baseline or during follow-up, we excluded also possible breast feeding women of the cohort. Finally, 11195 participants remained for the longitudinal analyses. This study was approved by the Institutional Review Boards of the University of Navarra. Informed consent was implied by the voluntary completion of the baseline questionnaire.

\section{Assessment of Dietary Exposure}

At baseline, participants completed a semi-quantitative food frequency questionnaire that has been validated previously in Spanish subjects. [28] There were nine options for the average frequency of intake of 136 food items in the previous year, based on typical portion sizes, ranging from never/almost never to at least six times per day. Nutrient intake was calculated using the most up-to-date food composition tables for Spain. [29, 30]

\section{Assessment of dietary pattern factors}

Since there is no definition of "a priori" Western dietary pattern, we used baseline dietary intake data using principal component analysis to identify dietary pattern factors among the participants of the SUN cohort as a methodological approach to explore our own data. The 136 food items included in the semi-quantitative food frequency questionnaire were grouped into 30 pre-defined food categories (See Appendix) using as a unit of measurement grams per day based on the participants' answers and the grams per servings of each food item. A 
principal component analysis (PCA) based on the stratified food groups was carried out to identify the major dietary patterns in the cohort. The food group "cookies" was excluded for the subsequent analyses because its measure of sampling adequacy was lower than 0.70 . The approach used to determine the number of factors to be extracted was the scree plot examination. [31] To achieve better interpretability, we used an orthogonal rotation procedure (varimax rotation) obtaining results in factors (i.e. dietary patterns) that are not correlated with each other. We determined the number of factors retained by the amount of variation explained by each pattern and the natural interpretation of each pattern generated. Food groups that loaded $>0.30$ were considered to be making a contribution to the factor. The factor score for each pattern was constructed by summing observed consumptions of the component food items weighted by their factor loadings. Thus, each individual received a factor score for each identified pattern. [31]

Twenty-four percent of the total variance was explained by the retained factors. We identified 2 major dietary pattern factors, and labeled them: the "Western" pattern (factor 1) and the "Mediterranean" pattern (factor 2). Those food items identified in the "Western" pattern were red meat, processed meats, eggs, sauces, pre-cooked food, fast food, caloric soft drinks, whole fat dairy, and potatoes. Those identified in the "Mediterranean" pattern (factor 2) included olive oil, poultry, fish, low fat dairy, legumes, fruits, and vegetables (Table 1). 
Table 1. Pearson's correlation coefficients for the relationship between baseline food consumption and factors representing dietary patterns $(n=17197)$

\section{Dietary Patterns}

\begin{tabular}{lcc} 
& Factor 1("Western") & Factor 2 ("Mediterranean") \\
\hline Olive oil (g/day) & 0.02 & $\mathbf{0 . 3 2}$ \\
Poultry (g/day) & 0.20 & $\mathbf{0 . 3 8}$ \\
Red meat (g/day) & $\mathbf{0 . 5 4}$ & 0.12 \\
Processed meat (g/day) & $\mathbf{0 . 5 0}$ & 0.20 \\
Eggs (g/day) & $\mathbf{0 . 3 7}$ & 0.11 \\
Fish (g/day) & -0.01 & $\mathbf{0 . 5 9}$ \\
Sauces (g/day) & $\mathbf{0 . 4 2}$ & 0.01 \\
Pre-cooked foods (g/day) & $\mathbf{0 . 4 1}$ & -0.04 \\
Fast food (g/day) & $\mathbf{0 . 5 7}$ & -0.08 \\
Caloric soft drinks (g/day) & $\mathbf{0 . 3 5}$ & -0.16 \\
Commercial sweets (g/day) & $\mathbf{0 . 4 0}$ & -0.17 \\
Whole dairy (g/day) & $\mathbf{0 . 4 3}$ & -0.21 \\
Low fat dairy (g/day) & $\mathbf{- 0 . 3 1}$ & $\mathbf{0 . 3 7}$ \\
Legumes (g/day) & 0.19 & $\mathbf{0 . 3 0}$ \\
Vegetables (g/day) & $\mathbf{0 . 4 5}$ & $\mathbf{0 . 6 8}$ \\
Fruits (g/day) & & $\mathbf{0 . 5 4}$ \\
\hline & & \\
\hline
\end{tabular}

Assessment of Non-dietary Variables

The baseline evaluation also included questions inquiring about medical history, health habits, lifestyle and socio-demographic variables. There were 46 items for men and 54 for women. 
Participants were categorized as smokers, non-smokers or former smokers. The number of hours spent in sedentary activities such as daily hours of television viewing, daily hours driving, daily hours sitting down and daily hours napping, were quantified. Physical activity was collected through a validated questionnaire that included information about 17 activities such as walking, running, cycling, swimming, judo, soccer, skiing or sailing. . To quantify the volume of activity during leisure time, an activity metabolic equivalent (MET) index was computed by assigning a multiple of resting metabolic rate (MET score) to each activity, [32] and the weekly time spent in each of the activities was multiplied by the MET score specific to each activity, and then summed for overall activity, obtaining a value of overall weekly MET-hours. Leisure time physical activity estimated with the questionnaire was previously validated by our group using a tri-axial accelerometer as the gold standard. Physical activity during leisure time (estimated as MET-h/week) derived from the questionnaire moderately correlated with Kcal/day assessed through the accelerometer (Spearman's rho $=0.507,95 \%$ CI: 0.232 to $0.707, p<0.001)$. [33]

\section{Assessment of the outcomes}

Costs of foods were derived from the Ministry of Industry, Tourism and Commerce of Spain. [34] Monthly reported national average costs for each food item were averaged to annual costs of that item, and the appropriate costs were used for the year that the participants completed the baseline questionnaire to control for variations in prices between years. The prices of a small quantity of items (18.3\%) that were not reported by the Ministry were taken from current average prices from national supermarket websites. The total daily costs of food for each participant were calculated by multiplying the cost of each food item per gram, by the quantity of grams the participant indicated that he or she consumed in an average day. 
Baseline weight was self-reported at the time of the baseline questionnaire. Body weight at follow-up was self-reported at the time of the follow-up questionnaires; two, four and/or six years after the baseline questionnaires (median 28 months). The methodology of self-reported weight assessment and its reliability and validity was examined in a sub-sample of the cohort previously. The mean relative error in self-reported weight was $1.45 \%$, and the correlation coefficient between measured and self-reported weight was 0.99 (95\% confidence interval: 0.98 to 0.99$)$. [35]

The outcomes were 1) costs defined as Euros (€) per $1000 \mathrm{kcal}, 2)$ self-reported increase in body weight of at least $3 \mathrm{~kg}$ in the past five years (enough amount of weight gain that may not be the result of the minor within-subject changes depending on the time a participant answered the questionnaire), 3) increase in body weight of at least $0.6 \mathrm{~kg} / \mathrm{year}$ ( $\geq 3 \mathrm{~kg} / 5$ years) during follow-up, categorized as a dichotomous variable (weight gain 0.6 $\mathrm{kg} /$ year, yes or no).

\section{Statistical Analyses}

Participants were divided into quintiles according to the obtained scores for a "Western" (factor 1) and "Mediterranean" (factor 2) dietary patterns. Linear regression analysis was used to analyze the association between dietary pattern quintiles (Q) and the cost per $1000 \mathrm{kcal}$, using the first quintile as the reference category, and results were adjusted for age, sex, years of education (3 categories), employment and marital status. Non-conditional logistic regression analysis was used to calculate the crude odds ratios (OR) and 95\% CI of a weight gain of at least $3 \mathrm{~kg}$ in the past 5 years, the age-and sex-adjusted OR, and the multivariateadjusted OR (adjusted for age (years), sex, total energy intake (kcal/day), leisure time physical activity (MET-h/wk), smoking status (non-smoker, smoker, former smoker), snacking (no, yes), alcohol (\% energy/day), sedentary time (hrs/day) which included daily hours of television viewing, daily hours driving, daily hours sitting and daily hours napping). 
The same was done using weight gain of at least $0.6 \mathrm{~kg} /$ year during follow-up as the outcome, with the addition of baseline BMI $\left(\mathrm{kg} / \mathrm{m}^{\wedge} 2\right)$ to the multivariate analysis. Linear trends were tested for significance by using the median value of each quintile of cost and treating it as a continuous variable.

All $\mathrm{p}$ values presented are 2-tailed; $p<0.05$ was considered statistically significant. Analyses were performed with SPSS version 15.0 (SPSS Inc, Chicago, IL).

\section{RESULTS}

Participants with the highest cost of daily food consumption tended to be older (Q5 vs Q1: 42 vs $35 \mathrm{y}$ ), have a higher BMI at baseline (Q5 vs Q1: 24 vs $23 \mathrm{~kg} / \mathrm{m}^{\wedge} 2$ ) but lower total daily energy intake (Q5 vs Q1: 2032 vs $2607 \mathrm{kcal} / \mathrm{d}$ ) and lower energy-density. They were more likely to be female (Q5 vs Q1: 68\% vs 52\%), snacked less between meals (Q5 vs Q1: 28\% vs $39 \%$ ) and were more likely to be former smokers (Q5 vs Q1: 38\% vs 22\%) (Table 2). The energy profile of the participants who spent the most money on daily food consumption reflected a lower intake of all types of fat, alcohol and carbohydrates, but a higher intake of protein and fiber. Foods that were more highly represented in the diet of the participants who spent more money on daily food consumption included vegetables, fruits, whole wheat bread and nuts. Those foods more highly represented among those participants who spent less money on daily food consumption included cereals, eggs, sauces, cookies, sugar, commercial sweets and chocolate. Those who spent more money ate more total meat products; they ate more fish, poultry and processed meats. Those who spent less money for daily food consumption ate more fast food. The participants with a higher total cost had a higher consumption of low fat dairy, olive oil and pre-cooked foods as opposed to those with lower total cost who had a higher consumption of whole dairy and other vegetable oils different from olive oil. The higher spending participants also consumed more caloric beverages such as soft drinks, fruit juices and alcoholic beverages (Table 2). 
Table 2. Characteristics of participants according to daily food consumption costs

\begin{tabular}{|c|c|c|c|c|c|c|}
\hline \multirow[b]{2}{*}{ Variables } & \multicolumn{6}{|c|}{ Quintiles of daily food consumption costs ( $€ / 1000$ kcal $)$} \\
\hline & $\begin{array}{l}1 \text { (lowest) } \\
(\mathrm{n}=3440)\end{array}$ & $\begin{array}{l}2 \\
(n=3439)\end{array}$ & $\begin{array}{l}3 \\
(n=3440)\end{array}$ & $\begin{array}{l}4 \\
(n=3438)\end{array}$ & $\begin{array}{l}5 \\
(n=3440)\end{array}$ & $\mathrm{P}$ value $^{\mathrm{I}}$ \\
\hline $\begin{array}{l}\text { Price } \\
\text { (Euros/1000kcal) }\end{array}$ & $\leq 2.5$ & $2.51-2.81$ & $2.82-3.16$ & $3.17-3.65$ & $\geq 3.66$ & \\
\hline Men $(\%)$ & 48.1 & 44.1 & 40.2 & 37.3 & 32.1 & $<0.001$ \\
\hline Age (years) & $35.0(11.2)$ & $36.9(11.6)$ & $38.9(12.0)$ & $40.1(12.2)$ & $42.2(12.9)$ & $<0.001$ \\
\hline $\operatorname{BMI}\left(\mathrm{kg} / \mathrm{m}^{\wedge} 2\right)$ & $23.0(3.3)$ & $23.4(3.4)$ & $23.6(3.5)$ & $23.8(3.5)$ & $24.2(3.8)$ & $<0.001$ \\
\hline Weight $(\mathrm{kg})$ & $67.3(16.0)$ & $67.6(16.3)$ & $67.5(16.1)$ & $68.0(17.3)$ & $68.0(16.9)$ & 0.26 \\
\hline $\begin{array}{l}\text { Total energy intake } \\
\text { (kcal/day) }\end{array}$ & 2607 (606) & 2477 (590) & $2383(580)$ & $2249(574)$ & $2032(599)$ & $<0.001$ \\
\hline $\begin{array}{l}\text { Energy density } \\
(\mathrm{kcal} / \mathrm{g})\end{array}$ & $1.3(0.3)$ & $1.2(0.2)$ & $1.1(0.2)$ & $0.96(0.2)$ & $0.82(0.2)$ & $<0.001$ \\
\hline Snacking (\%) & 38.6 & 37.4 & 32.3 & 31.8 & 28.3 & $<0.001$ \\
\hline $\begin{array}{l}\text { Sedentary } \\
\text { time }^{2} \text { (hrs/day) }\end{array}$ & $6.0(2.3)$ & $5.9(2.1)$ & $5.8(2.0)$ & $5.7(2.1)$ & $5.5(2.1)$ & $<0.001$ \\
\hline $\begin{array}{l}\text { Physical activity } \\
\text { (MET-h/wk) }\end{array}$ & $23.5(21.3)$ & $24.0(21.7)$ & $24.2(22.5)$ & $24.2(22.0)$ & $24.9(22.3)$ & 0.12 \\
\hline
\end{tabular}


Table 2. (continued). Characteristics of participants according to daily food consumption costs

\section{Quintiles of daily food consumption costs ( $€ / 1000$ kcal $)$}

\begin{tabular}{|c|c|c|c|c|c|c|}
\hline Variables & $\begin{array}{l}1 \text { (lowest) } \\
(\mathrm{n}=3440)\end{array}$ & $\begin{array}{l}2 \\
(n=3439)\end{array}$ & $\begin{array}{l}3 \\
(n=3440)\end{array}$ & $\begin{array}{l}4 \\
(n=3438)\end{array}$ & $\begin{array}{l}5 \\
(n=3440)\end{array}$ & $\mathrm{P}_{\text {value }}{ }^{\mathrm{I}}$ \\
\hline Current smokers (\%) & 22.1 & 22.9 & 22.1 & 22.6 & 21.3 & $<0.001$ \\
\hline Former smokers (\%) & 22.4 & 26.9 & 29.9 & 32.8 & 38.4 & $<0.001$ \\
\hline $\begin{array}{l}\text { Total fat intake (\% of } \\
\text { energy) }\end{array}$ & $37.9(6.9)$ & $37.3(6.1)$ & $36.8(6.2)$ & $36.0(6.4)$ & $34.3(7.2)$ & $<0.001$ \\
\hline $\begin{array}{l}\text { Monounsaturated fat } \\
\text { (\% of energy) }\end{array}$ & $16.1(4.1)$ & $15.9(3.5)$ & $15.9(3.5)$ & $15.6(3.6)$ & $14.9(4.0)$ & $<0.001$ \\
\hline $\begin{array}{l}\text { Saturated fat (\% of } \\
\text { energy) }\end{array}$ & $12.9(3.0)$ & $12.9(3.1)$ & $12.7(3.1)$ & $12.2(3.2)$ & $11.4(3.6)$ & $<0.001$ \\
\hline $\begin{array}{l}\text { Polyunsaturated fat } \\
\text { (\% of energy) }\end{array}$ & $5.8(1.9)$ & $5.4(1.5)$ & $5.2(1.5)$ & $5.0(1.3)$ & $4.7(1.4)$ & $<0.001$ \\
\hline Protein (\% of energy) & $15.8(2.5)$ & $17.2(2.4)$ & $18.1(2.7)$ & $18.9(2.8)$ & $20.8(3.9)$ & $<0.001$ \\
\hline $\begin{array}{l}\text { Alcohol (\% of } \\
\text { energy) }\end{array}$ & $1.5(2.3)$ & $1.9(2.8)$ & $2.1(3.0)$ & $2.4(3.4)$ & $2.4(3.8)$ & $<0.001$ \\
\hline $\begin{array}{l}\text { Carbohydrates (\% of } \\
\text { energy) }\end{array}$ & $44.8(7.1)$ & $43.6(6.7)$ & $43.0(7.1)$ & $42.7(7.5)$ & $42.5(8.8)$ & $<0.001$ \\
\hline
\end{tabular}


Table 2. (continued). Characteristics of participants according to daily food consumption costs

\section{Quintiles of daily food consumption costs ( $€ / \mathbf{1 0 0 0}$ kcal)}

\begin{tabular}{lllllll}
\cline { 2 - 5 } Variables & 1 (lowest) & 2 & 3 & 4 & 5 & P value $^{1}$ \\
& $(\mathrm{n}=3440)$ & $(\mathrm{n}=3439)$ & $(\mathrm{n}=3440)$ & $(\mathrm{n}=3438)$ & $(\mathrm{n}=3440)$ & \\
\hline Fiber (g/day) & $21.0(7.6)$ & $24.3(8.0)$ & $26.9(8.8)$ & $29.8(9.9)$ & $34.7(12.8)$ & $<0.001$ \\
Vegetables & $316(176.2)$ & $426(200.9)$ & $505(236.0)$ & $597(285.7)$ & $780(451.1)$ & $<0.001$ \\
(g/day) & & & & & & \\
Fruits (g/day) & $203(179.0)$ & $281(207.2)$ & $341(244.9)$ & $402(292.1)$ & $495(375.8)$ & $<0.001$ \\
Legumes (g/day) & $22.0(20.5)$ & $22.9(17.8)$ & $23.1(17.2)$ & $23.4(16.7)$ & $22.5(15.8)$ & 0.01 \\
Cereals (g/day) & $124(85.5)$ & $105(66.2)$ & $99.8(60.9)$ & $93.0(55.1)$ & $84.9(47.6)$ & $<0.001$ \\
Whole wheat & $7.6(29.9)$ & $11.1(32.5)$ & $14.1(35.2)$ & $14.3(29.6)$ & $17.7(29.6)$ & $<0.001$ \\
bread (g/day) & & & & & & \\
Whole dairy & $271(236.7)$ & $227(205.6)$ & $192(175.7)$ & $164(150.5)$ & $135(117.6)$ & $<0.001$ \\
(g/day) & & & & & & \\
Low fat dairy & $152(221.2)$ & $192(236.3)$ & $219(236.1)$ & $255(245.5)$ & $308(267.1)$ & $<0.001$ \\
(g/day) & & & & & & \\
All meat (g/day) & $159(67.0)$ & $174(67.5)$ & $179(71.4)$ & $179(70.4)$ & $175(76.4)$ & $<0.001$ \\
Red meat (g/day) & $74.7(43.1)$ & $79.7(43.4)$ & $81.1(44.6)$ & $79.0(43.7)$ & $73.1(45.9)$ & $<0.001$ \\
\hline & & & & & & \\
\hline
\end{tabular}


Table 2. (continued). Characteristics of participants according to daily food consumption costs

\section{Quintiles of daily food consumption costs ( $€ / 1000 \mathrm{kcal})$}

\begin{tabular}{|c|c|c|c|c|c|c|}
\hline Variables & $\begin{array}{l}1 \text { (lowest) } \\
(n=3440)\end{array}$ & $\begin{array}{l}2 \\
(n=3439)\end{array}$ & $\begin{array}{l}3 \\
(n=3440)\end{array}$ & $\begin{array}{l}4 \\
(n=3438)\end{array}$ & $\begin{array}{l}5 \\
(n=3440)\end{array}$ & $\begin{array}{l}\mathrm{P} \\
\text { value }^{1}\end{array}$ \\
\hline $\begin{array}{l}\text { Poultry meat } \\
\text { (g/day) }\end{array}$ & $37.7(28.7)$ & $43.1(34.1)$ & $46.3(38.7)$ & $47.5(35.4)$ & $50.9(38.4)$ & $<0.001$ \\
\hline $\begin{array}{l}\text { Processed meats } \\
\text { (g/day) }\end{array}$ & $38.5(26.6)$ & $43.7(27.3)$ & $43.9(26.5)$ & $45.3(27.3)$ & $44.8(32.7)$ & $<0.001$ \\
\hline Eggs (g/day) & $26.0(20.6)$ & $23.9(15.1)$ & $23.4(14.0)$ & $22.5(14.3)$ & $20.9(13.0)$ & $<0.001$ \\
\hline Fish (g/day) & $60.6(34.9)$ & $83.0(41.2)$ & $98.7(46.8)$ & $112.4(54.0)$ & $138.6(81.2)$ & $<0.001$ \\
\hline Nuts (g/day) & $5.8(12.7)$ & $6.8(11.2)$ & $7.6(11.9)$ & $7.8(11.4)$ & $7.6(10.7)$ & $<0.001$ \\
\hline $\begin{array}{l}\text { Vegetable oil } \\
\text { (g/day) }\end{array}$ & $4.2(7.9)$ & $3.1(5.6)$ & $2.5(4.7)$ & $2.3(4.2)$ & $2.1(3.8)$ & $<0.001$ \\
\hline Olive Oil (g/day) & $19.7(17.7)$ & $18.3(14.7)$ & $18.5(14.0)$ & $18.2(12.7)$ & $18.0(11.9)$ & $<0.001$ \\
\hline $\begin{array}{l}\text { Pre-cooked foods } \\
\text { (g/day) }\end{array}$ & $23.3(30.1)$ & $29.0(37.0)$ & $30.4(40.7)$ & $30.1(42.5)$ & $32.0(58.9)$ & $<0.001$ \\
\hline
\end{tabular}


Table 2. (continued). Characteristics of participants according to daily food consumption costs

\section{Quintiles of daily food consumption costs ( $€ / 1000 \mathrm{kcal})$}

\begin{tabular}{|c|c|c|c|c|c|c|}
\hline Variables & $\begin{array}{l}1 \text { (lowest) } \\
(n=3440)\end{array}$ & $\begin{array}{l}2 \\
(n=3439)\end{array}$ & $\begin{array}{l}3 \\
(n=3440)\end{array}$ & $\begin{array}{l}4 \\
(n=3438)\end{array}$ & $\begin{array}{l}5 \\
(n=3440)\end{array}$ & $\mathrm{P}$ value ${ }^{\mathrm{I}}$ \\
\hline $\begin{array}{l}\text { Fast } \text { food }^{3} \\
\text { (g/day) }\end{array}$ & $22.2(22.2)$ & $22.0(19.3)$ & $21.2(19.3)$ & $19.5(16.9)$ & $17.5(17.9)$ & $<0.001$ \\
\hline Sauces (g/day) & $3.2(4.7)$ & $2.7(3.5)$ & $2.5(2.9)$ & $2.4(3.0)$ & $2.3(3.4)$ & $<0.001$ \\
\hline Cookies (g/day) & $27.0(44.7)$ & $19.4(28.4)$ & $16.7(22.6)$ & $15.5(20.1)$ & $14.8(17.0)$ & $<0.001$ \\
\hline $\begin{array}{l}\text { Sugary } \\
\text { products }^{4} \\
\text { (g/day) }\end{array}$ & $20.2(19.4)$ & $18.5(17.0)$ & $16.8(16.3)$ & $15.0(15.2)$ & $11.9(14.0)$ & $<0.001$ \\
\hline $\begin{array}{l}\text { Commercial } \\
\text { sweets (g/day) }\end{array}$ & $16.2(24.4)$ & $14.5(20.0)$ & $13.6(17.7)$ & $12.5(16.8)$ & $10.9(15.1)$ & $<0.001$ \\
\hline $\begin{array}{l}\text { Chocolate } \\
\text { (g/day) }\end{array}$ & $18.8(23.7)$ & $18.9(21.0)$ & $18.0(19.7)$ & $17.0(16.7)$ & $15.0(14.7)$ & $<0.001$ \\
\hline $\begin{array}{l}\text { Soft drinks } \\
\text { (g/day) }\end{array}$ & $63.3(120.0)$ & $56.9(105.0)$ & $59.1(113.6)$ & $58.7(101.8)$ & $84.1(169.0)$ & $<0.001$ \\
\hline $\begin{array}{l}\text { Fruit juice } \\
\text { (g/day) }\end{array}$ & $70.3(125.5)$ & $82.6(110.6)$ & $90.2(122.7)$ & 96.4 (127.7) & $108.3(135.4)$ & $<0.001$ \\
\hline
\end{tabular}

Continuous variables are expressed as means and (standard deviations) and categorical variables as percentages.

${ }^{1}$ The $\mathrm{p}$ value was calculated through ANOVA for continuous variables and through Chi squared test for categorical variables. ${ }^{2}$ Included daily hours of television viewing, daily hours driving, daily hours sitting, and daily hours napping during the day. Does not include hours slept at night. ${ }^{3}$ Sum of sausages, hamburgers and pizza. ${ }^{4}$ Sum of sugar, jam and honey. 
A higher score on the Mediterranean dietary pattern was positively associated with increased costs of daily food consumption after adjusting for age and sex, while a higher score on the Western dietary pattern was inversely associated with cost. We found that as participants adhered more to a Western dietary pattern (fifth quintile), they spent less money: $-0.64 €$ (0.80 \$) per $1000 \mathrm{kcal}(95 \% \mathrm{CI}:-0.68 €$ to $-0.61 €, p$ for trend $<0.001)$ on their daily food costs $v s$. the first quintile of adherence to a Western dietary pattern. Those participants who obtained the highest scores on the Mediterranean dietary pattern, spent more money on their daily food costs: $+0.71 €(+0.90 \$)$ per $1000 \mathrm{kcal}(95 \% \mathrm{CI}:+0.67 €$ to $+0.74 €, p$ for trend $<0.001)$ compared to those who had the lowest scores on this pattern. (Table 3). 
Table 3. Daily food costs according to quintiles of scores on the dietary patterns (multiple linear regression model)

\section{Quintiles of scores on the dietary patterns}

\begin{tabular}{|c|c|c|c|c|c|c|}
\hline "Western" dietary pattern & $\begin{array}{l}1 \text { (lowest) } \\
(\mathrm{n}=3439)\end{array}$ & $2(\mathrm{n}=3440)$ & $3(n=3439)$ & $4(n=3440)$ & $5(\mathrm{n}=3439)$ & $\begin{array}{l}\mathrm{P} \text { for } \\
\text { trend }\end{array}$ \\
\hline $\begin{array}{l}\text { Daily food costs (€/1000 kcal, } \\
\text { mean; (SD)) }\end{array}$ & $3.54(0.91)$ & $3.22(0.73)$ & $3.03(0.69)$ & $2.90(0.60)$ & $2.77(0.59)$ & \\
\hline $\begin{array}{l}\text { Crude (regression coefficient } \beta \text {, } \\
(\mathbf{9 5 \%} \mathbf{C I}))\end{array}$ & 0 (Ref) & $-0.32(-0.35$ to -0.29$)$ & $-0.51(-0.55$ to -0.48$)$ & $-0.65(-0.68$ to -0.61$)$ & $-0.77(-0.81$ to -0.74$)$ & $<0.001$ \\
\hline Age- and sex-adjusted $(95 \%$ CI) & 0 (Ref) & $-0.30(-0.33$ to -0.26$)$ & $-0.46(-0.49$ to -0.43$)$ & $-0.57(-0.60$ to -0.53$)$ & $-0.65(-0.68$ to -0.61$)$ & $<0.001$ \\
\hline Multivariate* adjusted (95\% CI) & 0 (Ref) & $-0.30(-0.33$ to -0.26$)$ & $-0.46(-0.49$ to -0.42$)$ & $-0.57(-0.60$ to -0.53$)$ & $-0.64(-0.68$ to -0.61$)$ & $<0.001$ \\
\hline $\begin{array}{l}\text { "Mediterranean" dietary } \\
\text { pattern }\end{array}$ & $\begin{array}{l}1 \text { (lowest) } \\
(\mathrm{n}=3439)\end{array}$ & $2(\mathrm{n}=3440)$ & $3(n=3439)$ & $4(n=3440)$ & $5(n=3439)$ & $\begin{array}{l}\mathrm{P} \text { for } \\
\text { trend }\end{array}$ \\
\hline $\begin{array}{l}\text { Daily food costs (€/1000 kcal, } \\
\text { mean; (SD)) }\end{array}$ & $2.75(0.70)$ & $2.93(0.68)$ & $3.04(0.68)$ & $3.22(0.72)$ & $3.52(0.79)$ & \\
\hline $\begin{array}{l}\text { Crude (regression coefficient } \beta \text {, } \\
(\mathbf{9 5 \%} \mathbf{C I}))\end{array}$ & 0 (Ref) & $0.18(0.15$ to 0.22$)$ & $0.29(0.25$ to 0.32$)$ & $0.47(0.44$ to 0.51$)$ & $0.77(0.74$ to 0.81$)$ & $<0.001$ \\
\hline Age- and sex -adjusted (95\% CI) & 0 (Ref) & $0.16(0.13$ to 0.19$)$ & $0.25(0.21$ to 0.28$)$ & $0.41(0.38$ to 0.44$)$ & $0.69(0.66$ to 0.73$)$ & $<0.001$ \\
\hline Multivariate* adjusted $(95 \%$ CI) & 0 (Ref) & $0.17(0.13$ to 0.20$)$ & $0.25(0.22$ to 0.29$)$ & $0.42(0.39$ to 0.45$)$ & $0.71(0.67$ to 0.74$)$ & $<0.001$ \\
\hline
\end{tabular}

SD: standard deviation; 95\% C.I.: 95\% confidence interval.

*Adjusted for age, sex, years of education, marital status, and employment. 
Continuous variable analysis revealed that for every additional standard deviation of adhesion score to the Western dietary pattern, the adjusted cost per $1000 \mathrm{kcal}$ decreased by $-0.21 €(-0.26 \$)(95 \% \mathrm{CI}$ : $0.23 €$ to $-0.20 €)$, whereas for every additional standard deviation of adhesion score to the Mediterranean dietary pattern, the cost per $1000 \mathrm{kcal}$ increased by $+0.27 €(+0.34 \$)(95 \% \mathrm{CI}:+0.26 €$ to $+0.28 €)$.

In stratified analyses, the association between the Western dietary pattern and a lower daily food cost was stronger among women and younger ( $<37$ year; median) participants ( $\mathrm{p}$ for interaction: $<0.001$ in both cases). Similarly, the association between the Mediterranean dietary pattern and lower daily food cost was stronger among women and younger ( $<37$ years; median) participants ( $\mathrm{p}$ for interaction: $<0.001$ and 0.020 , respectively).

To demonstrate the association between daily food consumption costs and adherence to dietary patterns, the quintiles of daily food consumption costs were grouped as those spending the least (Q1), spending the most (Q5) and the three intermediate quintiles were merged into one group (Q2-Q4) (Figure 1). As higher scores on the Mediterranean diet increased the cost of daily food consumption also increased, whereas the higher the scores on the Western diet the lower the daily food consumption costs.

There were 5,319 (30.9\%) participants reporting a weight gain of at least $3 \mathrm{~kg}$ in the five years previous to the baseline questionnaire. There was a tendency towards an inverse crude association between weight gain and the daily food consumption costs that was not significant. The multivariate-adjusted OR for those participants who spent the most money was 1.13 (95\% CI: 0.99-1.29, $p$ for trend 0.146) compared to those who spent the least (Table 4). 
Table 4. Odds ratios (95\% Confidence Intervals) for $\geq 3 \mathrm{~kg}$ weight gain within the past five years

\begin{tabular}{|c|c|c|c|c|c|c|}
\hline & \multicolumn{6}{|c|}{ Quintiles of daily food consumption costs (€/1000 kcal) } \\
\hline & $\begin{array}{l}1 \text { (lowest) } \\
(n=3440)\end{array}$ & $\begin{array}{l}2 \\
(n=3439)\end{array}$ & $\begin{array}{l}3 \\
(n=3440)\end{array}$ & $\begin{array}{l}4 \\
(n=3438)\end{array}$ & $\begin{array}{l}5 \\
(n=3440)\end{array}$ & $\mathrm{P}$ for trend \\
\hline $\begin{array}{l}\text { Cost of daily food consumption } \\
(€ / 1000 \text { kcal, median) }\end{array}$ & 2.2 & 2.7 & 3.0 & 3.4 & 4.1 & \\
\hline Cases & 1073 & 1135 & 1041 & 1066 & 1004 & \\
\hline Crude OR (95\% CI) & 1 (Ref.) & $1.09(0.98-1.20)$ & $0.96(0.86-1.06)$ & $0.99(0.90-1.10)$ & $0.91(0.82-1.01)$ & 0.013 \\
\hline Age-and sex-adjusted (95\% CI) & 1 (Ref.) & $1.11(1.00-1.23)$ & $1.00(0.89-1.10)$ & $1.04(0.94-1.15)$ & $0.97(0.88-1.08)$ & 0.303 \\
\hline Multivariate $^{1}$-adjusted $(95 \% \mathrm{CI})$ & 1 (Ref.) & $1.13(1.02-1.26)$ & $1.06(0.95-1.19)$ & $1.14(1.01-1.29)$ & $1.13(0.99-1.29)$ & 0.146 \\
\hline
\end{tabular}

\footnotetext{
${ }^{\mathrm{I}}$ The model included age (years), sex, total energy intake (kcal/day), leisure time physical activity (MET-h/wk), smoking status (non-smoker, smoker, former smoker), snacking (no, yes), alcohol (\% energy/day), sedentary time (hrs/day), years of education (3 categories), marital status, employment, and scores for the Mediterranean and Western dietary patterns.

95\% CI: 95\% Confidence Interval
} 
There were 3,473 (31\%) participants who reported a weight gain of at least $0.6 \mathrm{~kg}$ per year within the follow-up period. These data apparently suggested a direct association between daily food costs and weight gain, but they were also not statistically significant (Table 5).

Table 5. Odds ratios (95\% Confidence Intervals) for an average weight gain of at least $0.6 \mathrm{~kg} / \mathrm{year}$ during follow up (median follow-up=4.2 years) $(n=11,195)$

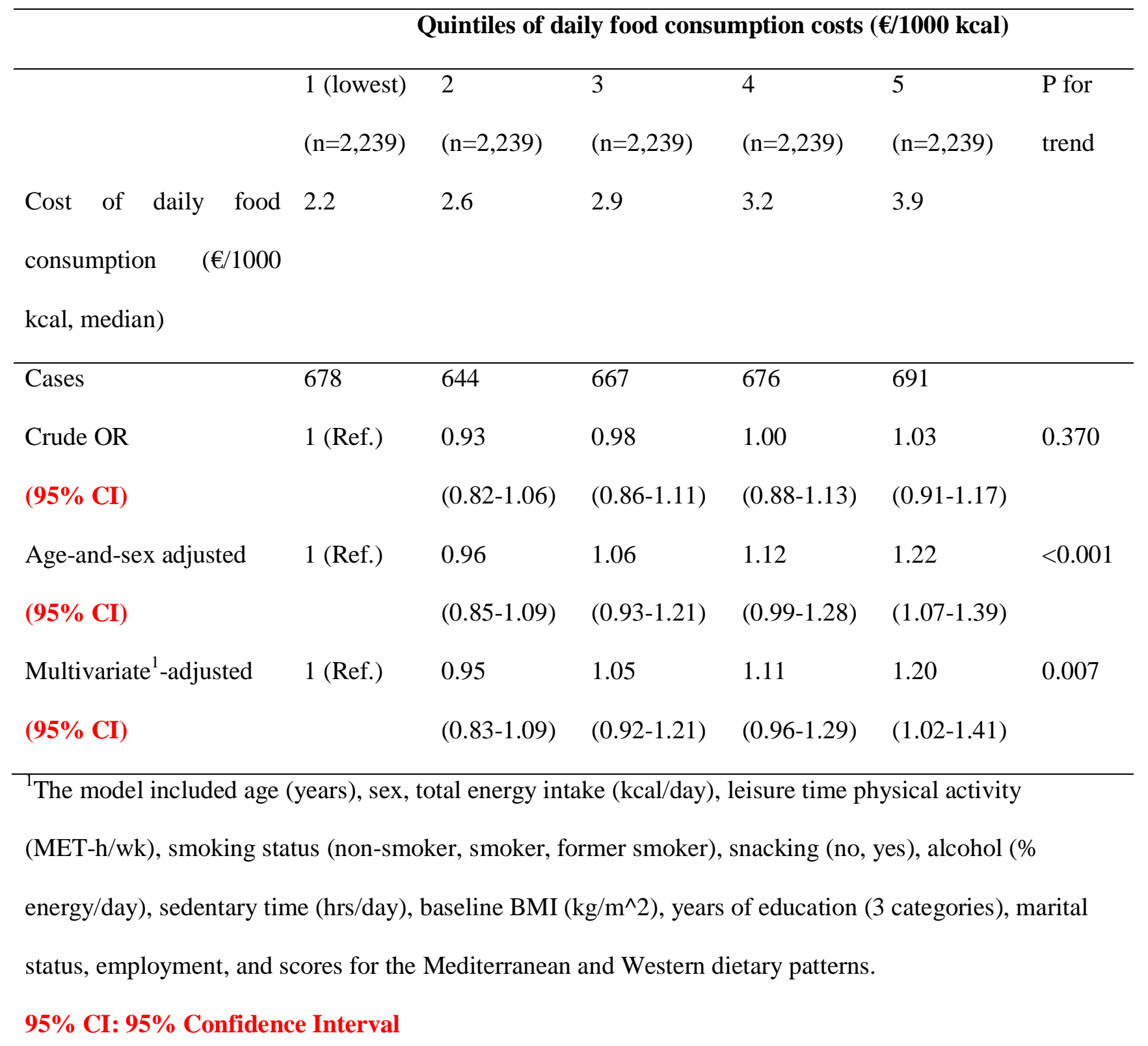


However, after adjusting for age, sex, total energy intake, leisure time physical activity, smoking status, snacking, alcohol intake, sedentary time, baseline BMI, years of education, marital status, employment, and scores on the Mediterranean and Western dietary pattern, a statistically significant association with higher odds of weight gain was found for the participants who had the highest daily food consumption costs (OR: 1.20; 95\% CI: 1.02-1.41, $p$ for trend 0.007).

When we analyzed weight change as a continuous variable adjusting for the same variables, the $\beta$ regression coefficient for change in kilograms/year for those with the highest daily food consumption costs was 0.11 (95\% CI: 0.01-0.21, $p$ for trend 0.009) compared to those who spent the least. When we conducted additional analyses stratifying by baseline BMI the results were the following: normoweight participants who had the highest daily food consumption costs (fifth quintile) presented an adjusted odds ratio for a weight gain of at least $0.6 \mathrm{~kg} /$ year during follow-up of 1.13 (95\% CI: 0.93-1.38; $p$ for trend $=$ 0.093), versus the lowest quintile of cost; while overweight/obese participants presented an adjusted odds ratio of $1.30(95 \%$ CI: $0.95-1.77 ; p$ for trend $=0.021 ; p$ for interaction $=0.11)$.

We conducted sensitivity analyses excluding those participants with co-morbidities at baseline such as cardiovascular disease, cancer and type- 2 diabetes $(n=1626)$. The main results did not change substantially.

\section{DISCUSSION}

Among a Mediterranean population of university graduates, participants who followed a Mediterranean dietary pattern spent more money on their daily food consumption. By contrast, the adhesion to a Western dietary pattern was less expensive. 
Our results are in agreement with previous studies in this area that have shown that low-energy-density diets, specifically of the Mediterranean dietary pattern, are associated with higher costs of daily food consumption. [13-15] Other researchers have found in cross sectional studies that closer adherence to a low-energy-density diet in association with higher daily food costs were associated with a lower BMI, [20] which prompted us to hypothesize that these would also be associated with lower likelihood of weight gain in our longitudinal study. However, unexpectedly higher daily food costs were associated with the risk of gaining at least $0.6 \mathrm{~kg}$ per year during follow-up. Although we have adjusted for potential confounding factors and our exposure variable took into account total energy intake, we cannot rule out the existence of residual or unmeasured confounding. This may include individual differences in metabolism and the ability to maintain or lose weight. Among the participants in the highest quintile who spent the most money on food, there was a significantly higher baseline BMI, which could contribute to this group's weight gain. The results of the analyses stratified by BMI might suggest that overweight/obese participants are more prone to develop weight gain per se due to other lifestyle, metabolic or genetic factors that render them more susceptible to subsequent weight gain. Another possible explanation for our results relies on the fact that while longitudinal analyses are useful for reducing reverse causation bias, it is important to acknowledge that they cannot eliminate this problem. [36] Overweight/obese individuals are aware of their weight status. As a consequence, they can respond by spending more money on their diets in order to improve it. Moreover, in our cohort, those participants with higher daily food costs presented a higher consumption of processed meats, precooked foods, soft drinks, and fruit juices. Previous studies conducted by our group with the SUN cohort participants have shown that factors such as consumption of soft drinks and fruit juices are associated with body weight gain. [37] Nonetheless, this finding deserves further investigation to prove its consistency in other populations.

Limitations of our study include the inability to generalize the data to the general Spanish population because of the high educational level of the participants. However, the homogeneity of the cohort population, all of similar educational background and presumably similar income level, is also a 
strength. Although similar educational level does not guarantee similar income, educational level has proven to be influential in the evaluation of socioeconomic status (SES). Specifically, compared to other socio-economic variables such as occupation, income and employment status, the strongest accountant for differences of SES is education. [38] Analyses that have taken into account education, occupation, income, and employment status have shown that education is the strongest determinant of socioeconomic differences in food habits. [39] While these subjects may have more money than the less educated Spanish population to spend on food, we would expect similar results because the subjects we examined all had a fairly similar income (i.e. restriction was used to control for SES as a confounding factor). Since our results are from an observational study, we cannot rule out the existence of residual confounding. However, we have adjusted for potential social confounders such as years of education, employment and marital status.

The dietary patterns identified by factor analysis represent specific dietary patterns of the study population but do not necessarily reflect the genuine Mediterranean and Western dietary patterns. In addition, factor analysis might involve some degree of subjectivity in selecting and grouping the food items, choosing the method of factor rotation, and determining the number of patterns to be retained. Variations in these criteria may induce variations in the composition of identified patterns and in the observed diet-cost associations. A low variance was explained by the retained factors. This is an inherent problem of the exploratory dietary pattern methodology. Though PCAs represent realworld dietary behaviours that may be of interest by themselves, they often seem to account only for a small proportion of total variance of foods. [40] Furthermore, the identified food groups represent fairly plausible Mediterranean and Western dietary patterns. Moreover, when we conducted sensitivity analyses using the hypothesis-oriented approach using the scored proposed by Trichopoulou et al. [41] and the identified food groups of the Western pattern of the Health Professionals Follow-up Study, [42-44] changes in the new results were negligible. 
Further, there will always be variation in cost of food between regions of the country, seasons of the year, and types of establishment the food is purchased from. By using averages of every month amongst multiple regions of the country, this should have been controlled to the extent possible. An additional limitation is that having only food intake data from the baseline questionnaire makes it difficult to ascertain that those subjects who gained weight during the follow up period did not change their diets considerably.

The increased presence of the fast food industry in Spain, and Europe as well, has made it more affordable, convenient and popular to consume a Western diet. The information that eating a traditional diet is not affordable in a region of the world where this dietary pattern originated and is well accepted is important in terms of future policy changes because the Mediterranean dietary pattern may become more appealing than the Western dietary pattern if it were to be made more affordable. It has been previously suggested, and implemented on a variety of scales in some regions of the United States and Europe, that small taxes on high energy density foods or advertisements for such foods, may serve as a deterrent to their consumption. The funds raised with such taxes have in the past been used for other public health measures. [45, 46] However, data derived from interviews of European policymakers on responses to the obesity epidemic showed that measures that were considered "upstream" such as taxes on unhealthy foods or subsidies on healthy foods were not seen as the most favorable, especially amongst those individuals in the private sector. Instead, there was a preference for more "downstream" measures such as education. [47] On the other hand, results from a China study found that changes in food prices, either through increases by taxation or decreases by subsidization, did affect food consumption. [48] Another study carried out in the cafeteria at the Harvard School of Public Health reported that subsidizing healthful meals and at the same time educating consumers about the importance of a healthy diet may contribute to a modest increase in the selection of healthy foods and meals that can be maintained beyond the periods of subsidy and promotion. [49] Consequently, these policies might help more people perceive that a healthy diet as a Mediterranean dietary pattern may not be necessarily more 
expensive, thereby increasing the probability that they will adopt this protective pattern. Probably the best strategy is to combine policy activities across the different public health approaches (upstream, midstream and down-stream), sectors and settings, and different levels of governances. [50] Nevertheless, more research is needed on the contribution of price to food purchasing behaviour and whether lower prices can serve as an impulse to consume more healthful products.

\section{WHAT THIS PAPER ADDS}

What is already known on this subject?

It is known that low-energy-density diets are associated with higher cost of daily food consumption. However, there is a scarcity of studies evaluating the relationship between food costs and adherence to different food patterns especially for the Mediterranean and Western dietary patterns.

\section{What does this study add?}

This study found that a healthy Mediterranean dietary pattern is more expensive [fifth quintile vs first quintile of scores of adherence: $+0.71 €(+0.90 \$)(95 \% \mathrm{CI}:+0.67 €$ to $+0.74 €)$ per $1000 \mathrm{kcal}]$ than a Westernized dietary pattern [fifth quintile $v s$ first quintile of scores of adherence: $-0.64 €(-0.80 \$)$ per $1000 \mathrm{kcal}$ ( $95 \% \mathrm{CI}:-0.68 €$ to $-0.61 €]$ after adjusting for potential confounders among healthy middle age Spanish graduates, thereby with similar level of income, those who better adhered to a Mediterranean dietary pattern expensed more money on food consumption than those who most adhered to a Westernized dietary pattern. Consequently, "upstream" measures such as taxes on unhealthy foods and/or subsidies on healthy foods may increase the probability of adopting a healthy dietary pattern.

\section{COMPETING INTERESTS}

We have no declarations of conflicting interest. 


\section{ACKNOWLEDGMENTS}

MAM-G, MB-R and CNL were responsible for study concept and design. MAMG and MB-R were responsible for acquisition and analysis of the data. MB-R and CNL were responsible for drafting of the manuscript. CNL, MB-R, AA, AS-V, MAM-G and AMP were responsible for critical revision of the manuscript for important intellectual content. MAMG was responsible for obtaining funding.

We thank all members of the SUN Study Group for administrative, technical and material support. We thank participants of the SUN Study for continued cooperation and participation. The SUN Study has received funding from the Spanish Ministry of Health (Grants PI070240; PI081943, and RD 06/0045), the Navarra Regional Government (projects 41/2005 and 36/2008) and the University of Navarra. CNL has been supported by the Paul Dudley White Traveling Fellowship, Harvard Medical School. 


\section{REFERENCES}

1. French SA. Pricing effects on food choices. J Nutr 2003;133:841S-43S.

2. Drewnowski A, Darmon N. Food choices and diet costs: an economic analysis. J Nutr 2005;135:9004.

3. De Lorgeril M, Salen P, Martin J, Monjaud I, Delaye J, Mamelle N. Mediterranean diet, traditional risk factors, and the rate of cardiovascular complications after myocardial infarction: final report of the Lyon Diet Heart Study. Circulation 1999;99:779-85.

4. Estruch R, Martinez-Gonzalez MA, Corella D, et al. Effects of a Mediterranean-style dieto n cardiovascular risk factors: a randomized trial. Ann Intern Med 2006;145:1-11.

5. Martínez-González M, Fernandez-Jarne E, Serrano-Martínez M, Martí A, Martínez JA, MartínMoreno JM. Mediterranean diet and reduction in the risk of a first acute myocardial infarction: an operational healthy dietary score. Eur J Nutr 2002;41:153-60.

6. Knoops KY, de Groot LC, Kromhout D, et al. Mediterranean diet, lifestyle factors, and 10-year mortality in elderly European men and women: the HALE project. JAMA 2004;292:1433-9.

7. Trichopoulou A, Lagiou P, Kuper H, Trichopoulous D. Cancer and Mediterranean dietary traditions. Cancer Epidemiol Biomarkers Prev 2000;9:869-73.

8. Martínez-González MA, Sánchez-Villegas A. The Emerging Role of Mediterranean Diets in Cardiovascular Epidemiology: Monounsaturated Fats, Olive Oil, Red Wine or the Whole Pattern? Eur J Epidemiol 2004;19:9-13.

9. Heidemann C, Schulze MB, Franco OH, van Dam RM, Mantzoros CS, Hu FB. Dietary patterns and risk of mortality from cardiovascular disease, cancer, anda 11 causes in a prospective cohorte of women. Circulation 2008;118:230-7.

10. Bray GA, Nielsen SJ, Popkin BM. Consumption of high fructose corn syrup in beverages may play a role in the epidemic of obesity. Am J Clin Nutr 2004;79:537-43. 
11. Gross LS, Ford ES, Liu S. Increased consumption of refined carbohydrates and the epidemic of type 2 diabetes in the United States: an ecological assessment. Am J Clin Nutr 2004;79:774-9.

12. Bowman SA, Gortmaker SL, Ebbeling CB, et al. Effects of fast-food consumption on energy intake and diet quality among children in a national household survey. Pediatrics 2004;113:112-8.

13. Drewnowski A, Darmon N. The economic of obesity: dietary energy density and energy cost. Am J Clin Nutr 2005;82:265S-73S.

14. Drewnowski A, Monsivais P, Maillot M, Darmon N. Low-energy-density diets are associated with higher diet quality and higher diet costs in French adults. J Am Diet Assoc 2007;107:1028-32.

15. Maillot M, Darmon N, Darmon M, Lafay L, Drewnowski A. Nutrient dense food groups have high energy costs: an economic approach to nutrient profiling. J Nutr 2007;137:1815-20.

16. Maillot M, Darmon N, Vieux F, Drewnowski A. Low energy density and high nutritional quality are each associated with higher diet costs in French adults. Am J Clin Nutr 2007;86:690-696.

17. Andrieu E, Darmon N, Drewnowski A. Low-cost diets: more energy, fewer nutrients. Eur J Clin Nutr 2006;60:434-6.

18. Ledikwe J, Blanck H, Khan L, Serdula M, Seymour J, Tohill B, Rolls B. Low-energy-density diets are associated with high diet quality in adults in the United States. J Am Diet Assoc 2006;106:117280.

19. Schroder H, Covas M, Elosua R, Mora J, Marrugat J. Diet quality and lifestyle associated with free selected low-energy density diets in a representative Spanish population. Eur J Clin Nutr. Published Online First: 11 July 2007. doi:10.1038/sj.ejcn.1602843

20. Schroder H, Marrugat J, Covas M. High monetary costs of dietary patterns associated with lower body mass index: a population-based study. Int J Obes 2006;30:1574-9.

21. Goulet J, Lamarche B, Lemieux S. A Nutritional Intervention Promoting a Mediterranean Food Pattern Does Not Affect Total Daily Dietary Cost in North American Women in Free-Living Conditions. J Nutr 2008;138:54-9. 
22. Joint WHO/FAO Expert Consultation: Diet, Nutrition and the Prevention of Chronic Diseases. Geneva: WHO Library Cataloguing-in-Publication Data; 2002.

23. Monsivais P, Drewnowski A. The rising cost of low-energy-density foods. J Am Diet Assoc 2007;107:2071-6.

24. Sánchez-Villegas A, Martínez JA, De Irala J, Martínez-González MA. Determinants of the adherence to an "a priori" defined Mediterranean dietary pattern. Eur J Nutr. 2002;41:249-57.

25. Schroder H, Fito M, Covas MI, REGICOR investigators. Association of fast food consumption with energy intake, diet quality, body mass index and the risk of obesity in a representative Mediterranean population. Br J Nutr 2007;98:1274-80.

26. Seguí-Gómez M, Fuente C, Vásquez Z, Irala J, Martínez-González MA. Cohort profile: The ‘Seguimiento Universidad de Navarra' (SUN) study. Int J Epidemiol 2006;35:1417-22.

27. Martínez-González MA; Sánchez-Villegas A; De Irala J; Marti A; Martínez JA. Mediterranean Diet and Stroke: Objectives and Design of the SUN Project. Nutr Neurosci 2002;5:65-73.

28. Martín-Moreno J, Boyle P, Gorgojo L. Development and validation of a food frequency questionnaire in Spain. Int J Epidemiol 1993;22:512-9.

29. Mataix J: Tabla de Composición de Alimentos. In Spanish. (Food Composition Tables). 4th edition. Granada: Universidad de Granada; 2003.

30. Moreiras O: Tablas de Composición de Alimentos. In Spanish. (Food Composition Tables). 9th ed. Madrid: Ediciones Pirámide; 2005.

31. Pett MA, Lackey NR, Sullivan JJ: Making sense of factor analysis: the use of factor analysis for instrument development in health care research. $1^{\text {st }}$ edition. Thousand Oaks: Sage Publications; 2003.

32. Ainsworth BE, Haskell WL, Whitt MC, et al. Compendium of physical activities: an update of activity codes and MET intensities. Med Sci Sports Exerc 2000;32:498S-504S. 
33. Martínez-González MA, López-Fontana C, Varo JJ, Sánchez-Villegas A, Martínez JA. Validation of the Spanish version of the physical activity questionnaire used in the Nurses' Health Study and Health Professionals' Follow-up Study. Public Health Nutr 2005;8:920-7.

34. Gobierno de España, Ministerio de Industria, Turismo y Comercio. Precios Medios Nacionales Ponderados de Venta al Público de Productos de Alimentación 2002-2008. In Spanish. (Spanish Government, Ministry of Industry, Tourism and Commerce. Average National Prices for Public Sale of Food Products 2002-2008). Internet: http://www.comercio.es/comercio/bienvenido/Comercio+Interior/Precios+y+Margenes+Comerciales $\underline{\text { Bases+de+Datos/pagPreciosmediosnacionalesponderadosdeventaalpublicodeproductosdealimentaci }}$ on.htm (accessed 8 July 2008).

35. Bes-Rastrollo M, Pérez Valdivieso JR, Sánchez-Villegas A, Alonso A, Martínez-González M. Validación del peso e índice de masa corporal auto-declarados de los participantes de una cohorte de graduados universitarios. In Spanish. (Validation of the self-reported weight and body mass index of the participants in a cohort of university graduates). Rev Esp Obes 2005;3:352-8.

36. Hu FB: Interpreting epidemiologic evidence and causal inference in obesity research. In Obesity epidemiology. Edited by Hu FB. New York: Oxford University Press, 2008:38-52.

37. Bes-Rastrollo M, Sanchez-Villegas A, Gomez-Gracia E, Martinez JA, Pajares RM, MartinezGonzalez MA. Predictors of weight gain in a Mediterranean cohort: the Seguimiento Universidad de Navarra Study. Am J Clin Nutr 2006;83:362-70.

38. De Irala J, Groth M. Johansson L, Oltersdorf U, Prättälä R, Martínez-González MA. A systematic review of socio-economic differences in food habits in Europe: consumption of fruit and vegetables. Eur J Clin Nutr 2000;54:706-14.

39. Roos E, Prättälä R, Lahelma E, Kleemola P, Pietinen P. Modern and healthy? Socioeconomic differences in the quality of diet. Eur J Clin Nutr. 1996;50:753-60.

40. Schulze MB, Hoffman K. Methodological approaches to study dietary patterns in relation to risk of coronary heart disease and stroke. Br J Nutr 2006; 95:860-9. 
41. Trichopoulou A, Costacou T, Bamia C, Trichopoulos D. Adhrence to a Mediterranean diet and survival in a Greek population. N Engl J Med 2003; 348:2599-608.

42. Sanchez-Villega a, Martinez JA, de Irala J, Martinez-Gonzalez MA. Determinants of the adherence to an "a priori” defined Mediterranean dietary pattern. Eur J Nutr 2002;41:249-57.

43. Lasheras C, Fernandez S, Patterson AM. Mediterranean diet and age with respect to overall survival in institutionalized, non-smoking elderly people. Am J Clin Nutr 2000;71:987-92.

44. Hu FB, Rimm EB, Stampfer MJ, Ascherio A, Spiegelman D, Willett WC. Prospective study of major dietary patterns and risk of coronary heart disease in men. Am J Clin Nutr 2000;72:912-21.

45. Jacobson MF, Brownell KD. Small Taxes on Soft Drinks and Snack Foods to Promote Health. Am J Public Health 2000;90:854-7.

46. Lobstein T, James P. Uso de los impuestos para promover una alimentación sana. In Spanish. (Use of taxes to promote a healthy diet). Diabetes Voice 2004;49:40-3.

47. Millstone E, Lobstein T. The PorGrow project: overall cross-national results, comparisons and implications. Obes Rev 2007;8: 29S-36S.

48. Guo X, Popkin BM, Mroz TA, Zhai F. Food price policy can favorably alter macronutrient intake in China. J Nutr 1999;129:994-1001.

49. Michels KB, Bloom BR, Riccardi P, Rosner BA, Willett WC. A study of the importance of education and cost incentives on individual food choices at the Harvard School of Public Health cafeteria. J Am Coll Nutr 2008;27:6-11.

50. Sacks G, Swinborn B, Lawrence. Obesity policy action framework and analysis grids fro a comprehensive policy approach to reducing obesity. Obes Rev 2008 [Epub ahead of print]. 
The Corresponding Author has the right to grant on behalf of all authors and does grant on behalf of all authors, an exclusive licence (or non exclusive for government employees) on a worldwide basis to the BMJ Publishing Group Ltd to permit this article (if accepted) to be published in JECH and any other BMJPGL products and sublicences such use and exploit all subsidiary rights, as set out in our licence (http://jmg.bmj.com/ifora/licence.pdf). 


\section{Figures}

Figure 1 . Price ${ }^{1}$ (Euros, €) per $1000 \mathrm{kcal}$ categorized by dietary patterns.

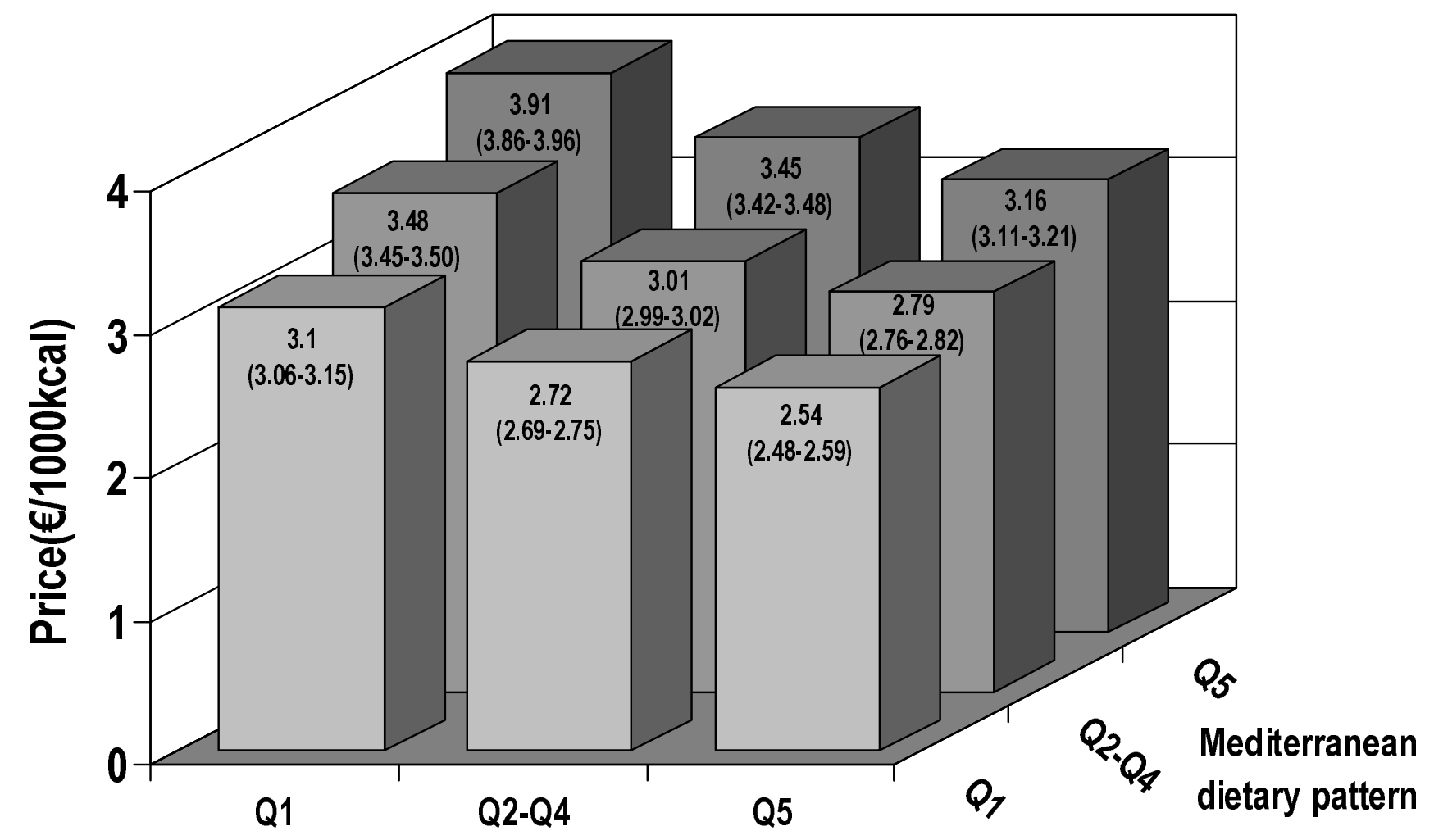

${ }^{1}$ Adjusted for age and sex.

Western dietary pattern 